\title{
A CONSTRUÇÃO DE UMA DEMOCRACIA COGNITIVA
}

\author{
antonio Carlos Caruso Ronca \\ Rogério da Costa
}

\begin{abstract}
Resumo: A construção de uma democracia cognitiva discute a produção e a difusão de conhecimentos que, através dos mais recentes meios de comunicação, não estão mais restritos ao âmbito das instituições de ensino. Diante disso, há uma exigência natural da sociedade para que essas instituições se apresentem não apenas como simples depositários do saber, mas como canais de acesso crítico aos conhecimentos e informações e encontrem, cada vez mais, caminhos para interferir na realidade.

Palavras-chave: educação; democracia; tecnologia e informação.

Abstract: The building of a cognitive democracy depends on the production and dissemination of knowledge. Thanks to the most recent innovations in communications, knowledge is no longer restricted in its scope to the realm of teaching institutions. This being the case, society is justified in its demand that these institutions act not as mere repositories of knowledge, but rather as accessible sources of critically important information, responsible for seeking out and finding new vehicles of influence.

Key words: education; democracy; technology and information.
\end{abstract}

A relação com o saber está sofrendo uma profunda mutação. Vive-se um momento em que a importância desse tema vem gerando um volume cada vez maior de discussões e publicações, por parte tanto das instituições de ensino e pesquisa como das empresas e da mídia em geral. Claro que, se hoje o conhecimento tornou-se um tema tão importante, é porque passou a ser percebido de outro modo. Ao se acompanhar, por exemplo, a curva das modificações dos saberes e conhecimentos até meados do último século, poder-se-ia dizer que um homem, durante seu ciclo de vida profissional, utilizava basicamente o que havia aprendido no momento de sua formação. Os conhecimentos requeridos no início de sua carreira permaneciam úteis e válidos ao longo do seu percurso de trabalho, sendo que a velocidade das inovações tecnológicas mantinha-se compatível com o ciclo de vida do trabalhador.

A partir dos anos 50, no entanto, constata-se uma defasagem crescente nessa relação, que se verifica com o incremento na curva de inovações tecnológicas que não mais pôde ser acompanhado pela curva humana de aprendizagem. Fica claro que os conhecimentos adquiridos no momento de uma formação passaram a não ser necessa- riamente válidos ao longo de uma carreira profissional. Muitos conhecimentos estão se renovando e outros têm sido constantemente construídos e modificados.

Isso remete, mais uma vez, à inquietação inicial deste artigo: por que os conhecimentos estão se tornando um tema tão importante e evidenciado na atualidade? Uma das respostas está no fato de que o fluxo de produção de conhecimentos é maior do que aquele que uma formação educacional e profissional regular pode dar conta. Hoje, os problemas devem ser abordados levando-se em conta a modificação e a renovação incessantes dos saberes, competências e conhecimentos. Enquanto os conhecimentos eram estáveis, passavam despercebidos e podia-se manter, com eles, uma relação igualmente estável. No momento em que se modificam - e com uma intensidade cada vez maior -, passam a ser foco de atenção e sua variação acaba tendo que ser incluída na visão estratégica das instituições de ensino e pesquisa. Uma instituição que pretenda assumir uma postura dinâmica e comprometida com os movimentos da sociedade precisa, obrigatoriamente, considerar o fluxo inovador de conhecimentos que afeta a formação e a pesquisa em geral. Porém, se os conhecimentos, os saberes e as competências estão se modifican- 
do, de que maneira as instituições poderiam incluir essa mudança em suas políticas internas?

Melhor seria indagar: qual tem sido até então a visão estratégica das instituições de ensino e pesquisa em relação aos conhecimentos? Uma resposta possível é que elas sempre desejaram, em nome da tradição, se consolidar como reserva dos saberes, como banco de conhecimentos, como fiel depositário do saber. Essa foi, na verdade, uma das tendências históricas que mais colaborou para a criação de instituições de ensino e pesquisa, em que a associação entre ocupar um espaço físico e ser o "lugar" do conhecimento sempre pareceu muito natural. Recentemente, o filósofo Michel Serres criticou o governo francês pela construção da grande Biblioteca Central em Paris, alegando se tratar de um velho sonho de estado imperial querendo ostentar uma Biblioteca de Babel, onde todo o saber da humanidade poderia ser reunido. De certa forma, este é o problema atualmente enfrentado pelas bibliotecas das instituições de pesquisa, como, por exemplo, o crescente acúmulo de teses e dissertações.

Ocorre que, hoje, uma instituição não pode pensar em dominar a totalidade dos saberes. Mesmo cada um dos seus setores, com toda a excelência que tenha, não pode abarcar a diversidade de conhecimentos que se expande a cada dia. Há, portanto, uma cisão em curso entre, por um lado, a idéia de preservação dos saberes e, por outro, a de uma instituição de ensino e pesquisa que tem de lidar com um fluxo cada vez mais intenso de inovação dos conhecimentos.

Michel Serres, por exemplo, defende a preocupação não apenas com o acúmulo de saberes entre as paredes da instituição, mas, sobretudo, com a construção do maior número possível de alternativas de comunicação, de canais de circulação do conhecimento, de aberturas para o mundo. Afinal, o conhecimento cresce e se enriquece à medida que circula; as idéias se proliferam quando se encontram. Isso significa que não basta acumular conhecimentos, mas sim que é preciso, acima de tudo, multiplicar os meios que os tornem acessíveis. Em outras palavras, é necessário inventar a democracia cognitiva, cujo lema seria o acesso de todos ao saber de todos. Nesse sentido, é a interconexão entre pesquisadores que favorece os processos de inteligência coletiva, que nada mais é do que a valorização, a utilização ótima e a colocação em sinergia das competências, das imaginações e das energias intelectuais, qualquer que seja sua diversidade qualitativa e onde quer que elas se encontrem. Esse ideal passa por uma prática cotidiana de troca de experiências, por novas for- mas de organização e de coordenação flexíveis, tudo isso em função da otimização do acesso aos conhecimentos.

Deve-se lembrar que as mutações em nossa relação com os saberes acompanham o que se convencionou a chamar de economia do imaterial. São duas dimensões que se estabelecem ao mesmo tempo, uma como correlata da outra. A economia do imaterial constitui-se no plano dos intangíveis, como economia dos serviços, do lazer, das imagens, das informações, de tudo aquilo que não gira em torno da idéia de produto, tal como concebida pela economia clássica.

O conhecimento e a informação apresentam-se como fator-chave nesse processo, pois são, justamente, o imaterial e o suporte da produção imaterial de um número cada vez maior de profissionais, incluindo aqueles que trabalham de alguma maneira com as mais diversas tecnologias - analistas de negócios, advogados, especialistas em informação em arquivos e bibliotecas, analistas políticos e jornalistas, estudantes e professores, entre outros. Hoje, mais de $60 \%$ dos profissionais de nossa sociedade contemporânea passam mais de um terço de seu tempo extraindo, compreendendo, transformando e comunicando informações.

Mais profundamente, o que se observa é que tanto a natureza dos novos suportes de comunicação como as exigências da vida econômica reclamam por uma nova concepção do saber. O que acontece hoje é que o cotidiano das inovações tecnológicas acaba conduzindo a uma perspectiva na qual os conhecimentos são cada vez mais singulares e pertinentes a este ou àquele contexto. Os percursos e perfis de conhecimentos e competências adquiridos por uma pessoa são todos singulares e podem cada vez menos se restringir a programas ou cursos válidos para todos. Hoje, habitam-se espaços de conhecimentos abertos, contínuos e não-lineares, que se reorganizam segundo o contexto de cada um. A pesquisa, por seu lado, torna-se cada vez mais transdisciplinar, desafiando toda a organização hierárquica das disciplinas conhecidas.

\section{AS DEMANDAS DA SOCIEDADE SÃO UM DESAFIO ÀS INSTITUIÇÕES}

As desordens da economia, assim como o ritmo precipitado das evoluções científicas e técnicas, determinam uma aceleração geral da demanda por conhecimentos na sociedade. Mais do que nunca, a produção de conhecimentos diz respeito à vida de todas as pessoas. Deve-se reconhecer, no entanto, que há uma crescente dificuldade em se prever o curso atual dos saberes, tal a quantidade 
de inovações que chegam cotidianamente. Por isso, atualmente é preciso, acima de tudo, incentivar processos, trajetos e cooperações. Afinal, todos sabem que o tempo necessário para se homologar novos diplomas e para se constituir os cursos que os habilitam está defasado em relação ao ritmo de evolução dos conhecimentos.

$\mathrm{O}$ que fazer? Os indivíduos estão tentando resolver a seu modo esse problema, aprendendo cada vez mais fora das fileiras acadêmicas. Isso apenas comprova que a demanda por formação nunca foi tão grande. As universidades transbordam e os dispositivos de formação profissional e de pesquisa estão saturados. Poder-se-ia dizer que metade da sociedade está ou gostaria de estar freqüentando uma instituição de ensino. No entanto, não é possível aumentar o número de formadores proporcionalmente à demanda de formação, sendo que essa demanda não é apenas quantitativa, mas também qualitativa. Isso significa a existência de uma necessidade crescente de diversificação e de personalização da formação, que, como lembra o filósofo Pierre Lévy, inviabiliza soluções do tipo industrialista, que tentam responder à demanda com um simples aumento da oferta de cursos e disciplinas. Essas últimas, mesmo nos programas de pós-graduação, já são percebidas como pré-formatadas e, na maior parte dos casos, distanciadas dos projetos de pesquisa dos estudantes.

Entretanto, nesse início de século XXI, o que significa exatamente a noção de "pós-graduação"? Como foi possível constatar em recente pesquisa realizada pelo Datafolha, atualmente o conceito de pós-graduação ligase cada vez mais ao trabalho, à carreira e à formação profissional (Folha de S.Paulo, 03/02/02). A ascensão profissional tem sido componente essencial daqueles que procuram uma formação pós-graduada, fato que pode ser atribuído às exigências das empresas, às mudanças de empregos ou à simples projeção profissional no mercado. A pesquisa do Datafolha mostra que $78 \%$ dos que procuram esse tipo de formação atribuem sua decisão à busca de um melhor posicionamento na carreira e no mercado de trabalho. O reforço dessa tendência vem da efetiva mudança na vida profissional - como promoções e aumento salarial - experimentada por aqueles que já realizaram um curso de pós-graduação. A pesquisa menciona que, na última década, o número de mestres e doutores cresceu, em média, mais de $250 \%$ e a oferta de cursos de especialização e MBAs também teve expressivo aumento.

Outro fato marcante é a procura de cursos de pós-graduação em áreas distintas das formações iniciais dos alunos, complementares às carreiras desses profissionais. É comum, por exemplo, encontrar um graduado em engenharia cursando pós-graduação em administração, alguém com formação em marketing seguindo uma pós-graduação em tecnologias da informação, um recém-formado em direito buscando uma especialização em biogenética, etc. Essa transdisciplinaridade é a maneira encontrada pelo profissional de suprir exigências percebidas em seu diaa-dia, como parte da interpretação que ele dá às tendências não apenas do mercado, mas sobretudo das inovações que se traduzem em conhecimentos.

A nova LDB - Lei de Diretrizes e Bases da Educação Nacional é outro importante fator que tem contribuído para a mudança de características da pós-graduação, pois exige que um terço do quadro docente das instituições de ensino superior tenha título de mestre ou doutor. Isso, logicamente, ampliou a procura por cursos de mestrado e doutorado por parte de muitos professores de cursos de graduação, sobretudo das instituições de ensino superior privadas. Por outro lado, existe também uma nítida questão competitiva e de mercado quando nos referimos ao aumento do número de professores titulados no ensino superior privado, expresso numa demanda crescente por esse tipo de profissional.

Com esse novo perfil de estudantes, a tarefa dos docentes dos cursos de mestrado e doutorado tornou-se bem mais complexa. O que deveria ser um curso voltado para a formação de pesquisadores e para o estímulo da pesquisa científica, tem agora que se desdobrar numa conversação constante com a esfera do trabalho e suas demandas específicas. Para muitos docentes ainda é novidade encontrar em suas turmas estudantes que chegam de outras áreas, com as mais variadas expectativas.

Diante da revolução científica e tecnológica que vivemos, muitas perguntas devem ser colocadas aos programas de pós-graduação. Quais as novas tendências de cada área? Que profissionais têm procurado estes programas? Qual a capacidade dos programas em receberem propostas de pesquisa de profissionais oriundos de outras áreas? $\mathrm{O}$ crescimento da demanda por conhecimentos transdisciplinares não deveria exigir uma maior preparação para trabalhos em equipe, com experiências e competências compartilhadas? Os programas de pós-graduação estão dispostos e capacitados a acolher essa recente e legítima demanda social por uma formação diferenciada? A democracia cognitiva não passaria por um tal acolhimento? Não seria em direção a essa democracia, mais ampla - uma vez que inclui toda a sociedade - que as instituições de ensino superior deveriam caminhar, ao lado de bem-suce- 
didas iniciativas de democracia interna, como a vivenciada na PUC-SP? Estes questionamentos apontam para um dos princípios que devem nortear uma instituição de ensino e pesquisa: poder abrigar e responder aos múltiplos e diferenciados interesses da sociedade.

\section{A DISTRIBUIÇÃO DOS CONHECIMENTOS E A CONVERGÊNCIA CULTURAL NA INTERNET}

A Internet aparece aqui como um fator que não pode ser negligenciado, quando se pretende dar conta da demanda maciça e, ao mesmo tempo, personalizada atualmente existente. Neste sentido, não parece pertinente a distinção entre ensino presencial e ensino à distância, uma vez que o uso da rede mundial de computadores já vem se integrando a todas as formas e todos níveis de ensino. Constata-se, de forma irreversível, que a Internet dá acesso à rede de informações e conhecimentos que, muito em breve, se constituirá no próprio espaço comum do conhecimento. A expansão inigualável desse meio de comunicação marca uma mutação profunda vivenciada em relação à pesquisa, que se afirma cada vez mais como diagonal, transdisciplinar, coletiva, colaborativa, desenvolvida para além das fronteiras das instituições. Como prenuncia Pierre Lévy, isto nos levará de uma educação e uma formação estritamente institucionalizadas, para uma situação de troca generalizada dos saberes, de ensino da sociedade por si mesma, de reconhecimento autogerido, móvel e contextual das competências.

Já é possível perceber o papel e a importância da Internet na promoção de grandes redes de ensino, aprendizagem e pesquisa. A função de produção de conhecimentos e de difusão de informações encontra-se cada vez mais distribuída entre inúmeros agentes através da web. Atualmente, não apenas instituições de ensino superior contribuem com a disponibilização de conteúdo educativo e informativo na rede, mas também bibliotecas, museus, editoras, jornais, rádios, televisões, revistas, empresas e as mais diversas organizações. As empresas têm sido, nos últimos tempos, grandes promotoras de encontros, colóquios, congressos e debates por todo o mundo.

São muitos os atores e várias as iniciativas de se construir redes de conhecimento autenticado através da Internet. Valeria a pena mencionar alguns exemplos. Uma iniciativa interessante é a da seção dedicada à educação, do site do The New York Times (www.nytimes.com/learning/), que apresenta um grande número de cursos, incluindo artes, tecnologia, geografia, saúde, matemática, etc., além de fóruns de discussão, artigos e links para sites com temas relacionados, entre outros recursos. Outro exemplo é o site da enciclopédia Encarta, da Microsoft $<$ http://encarta. $\mathrm{msn} . \mathrm{com} / \mathrm{schollhouse} />$, que oferece cursos gratuitos nas mais variadas áreas, como artes, saúde, matemática, física e religião, com indicações de material complementar para cada curso, como referências na web, vídeos, literatura, artigos e museus. Enquanto o site do The Franklin Institute Museum $<$ http://sln.fi.edu/tfi/ $>$ oferece uma série de cursos on-line sobre ciência, a página eletrônica do Smithsonian Institution (www.si.edu) divulga dezenas de cursos sobre história da arte, educação e ciências, entre outros. O site da empresa de biotecnologia Celera, famosa pela disputa pelo mapeamento do código genético (www.celera.com), também disponibiliza uma grande quantidade de excelentes artigos científicos sobre as pesquisas do genoma humano.

Ao lado dessa nova tendência de distribuição na função de promoção e difusão dos conhecimentos, outra tendência igualmente interessante é a da convergência cultural, com instituições educacionais, empresas, mídias, bibliotecas, etc. agrupando-se em torno de uma mesma tarefa: oferecer conhecimento autenticado ao maior número possível de pessoas.

Um dos melhores exemplos desse novo tipo de parceria é a experiência desenvolvida pelo site Fathom.com (www.fathom.com), criado no início de 2001 por um consórcio de dez instituições formado pela Columbia University, London School of Economics and Political Science, Cambridge University, The British Library, Smithsonian Institution's National Museum of Natural History, The New York Public Library, University of Chicago, Americam Film Institute, Rand e Woods Hole Oceanographic Institute. O objetivo principal do Fathom.com é atrair pessoas interessadas para o interior de um circuito de capital de conhecimentos e expertises autenticadas, com o slogan "Você deseja participar do mundo das idéias não apenas porque elas são desafiadoras e contra-intuitivas ou complexas, mas porque você gosta disso, porque isso é bom para sua carreira, para sua alma, porque você pode". Nesse site encontram-se centenas de cursos on-line oferecidos pelas instituições consorciadas, com seus respectivos grupos de discussão e inúmeros produtos relativos ao conhecimento, como livros, CD-ROMs, vídeos, CDs, periódicos. Um sistema de indexação por proximidade permite ao usuário saber que cursos oferecidos relacionam-se com quais outros e que produtos, referentes a esses cursos, podem ser encontrados no próprio site, pos- 
sibilitando uma alternância entre pesquisa em profundidade e pesquisa tangencial. Ann Kirschner, presidente do consórcio, informa que o site recebe mais de 750 mil visitantes únicos mensais e que, ao final do primeiro ano de atividade, já conta com mais de 100 mil usuários recebendo regularmente e-mails.

Outro exemplo dessa tendência de convergência cultural é o do site Science Learning Network (www.sln.org), criado em 1996 pela National Science Foundation e pela empresa Unisys, reunindo um grupo composto por onze museus de várias partes do mundo, todos oferecendo programas de estudo, cursos para estudantes e professores e informações dos mais variados gêneros disponíveis na Internet. Oferece ainda uma área comum, onde os parceiros disponibilizam cursos completos sobre ciências e artes, além de links de interesse educativo.

Todo esse processo de multiplicação dos agentes produtores e difusores de conhecimento e de consórcios entre instituições culturais na Internet traduz um grande desafio: a democratização do acesso aos conteúdos autenticados.

\section{AS INSTITUIÇÕES E A CONSTRUÇÃO DA DEMOCRACIA COGNITIVA}

A noção de co-evolução mostra que as mudanças tecnológicas, além de exigirem uma adaptação das pessoas, demandam também uma co-evolução da coletividade social. Não se trata apenas de assimilar as novas tecnologias. Mais do que isso, a possibilidade de tal assimilação depende, em grande parte, da evolução do próprio coletivo. Para tanto, uma instituição de ensino, como coletividade que é, deverá dispor dos meios para agir sobre si mesma. Isso significa que as relações entre as pessoas deverão se modificar, a cultura estabelecida deverá sofrer evoluções, mas isso só será possível se as próprias instituições investirem positivamente nessas mudanças.

Assim, a universidade deve ser ela mesma um ator, um agente de inovação que reinterpreta seu meio por ocasião de eventos, de fatos imprevistos, descobrindo assim novos objetivos em função dos quais ela se reorganiza. Neste contexto, como conceber uma instituição de ensino e pesquisa enquanto agente inovador? Antes de mais nada, é necessário concebê-la como um ator que reinterpreta os dados, que não se limita mais ao ciclo automático informação-ação-objetivo.

Michel Authier (1998a), matemático e sociólogo, sustenta que esse ciclo se encerrou com o advento das redes de informação e que, numa visão mais adequada aos novos fatos:

- uma instituição de ensino está sempre imersa num espaço contínuo de informações;

- uma informação isolada não possui valor intrínseco;

- o tipo de associação que os indivíduos fazem entre as informações disponíveis é que determina o valor que elas podem ter contextualmente;

- em conseqüência, a avaliação de uma informação depende do modo como ela é associada;

- isso conduz a uma necessidade de multiplicação dos canais de comunicação, para que as associações e interpretações dos indivíduos possam ser confrontadas entre si. Traduzido de outra forma, uma instituição deve ter meios para imaginar possiveis.

Entretanto, como fazer para que cada indivíduo, cada agente dentro de uma instituição de ensino e pesquisa seja um foco de visão de possiveis desta própria instituição? Se forem fornecidos às pessoas dispositivos por meio dos quais elas consigam se ver e atuar junto aos seus pares como disseminadoras de saberes e competências e como fontes geradoras e transmissoras de conhecimentos, apenas nesta medida elas poderão ter uma margem de criatividade e de inovação que se reverta em favor do coletivo. E aqui reencontram-se as palavras de Michel Serres, quando o autor afirma que o fundamental para a sobrevivência sempre renovada de uma instituição são os canais de distribuição e comunicação. A nova dimensão da comunicação nas instituições deve compreender os processos coletivos de produção de sentido, pelos quais seus membros se engajam uns em relação aos outros. Se há um sistema em que a informação caminha sempre verticalmente, esta própria arquitetura de transmissão de informação e dados determinará a ausência de qualquer processo criativo. Se, ao contrário, for construído um sistema em que a transmissão das informações é circular ou horizontal, haverá sempre a possibilidade da contextualização dessa informação na ação de um indivíduo em relação a outro.

Uma autêntica democracia cognitiva exige não apenas esse grau de comunicação interna, mas também uma abertura em direção à sociedade e suas necessidades. Se a inteligência de uma instituição de ensino e pesquisa for realmente coletiva, ela será o fator que faz o conhecimento circular, que destitui o ideal capitalista de acumulação, que fortalece os canais de acesso aos saberes, que promove a inovação criteriosa. Isso inclui, também, um apro- 
fundamento no papel da assistência e dos serviços que a instituição de ensino e pesquisa presta à comunidade. Ela não deve ter um papel apenas assistencialista; precisa se constituir como verdadeiro e múltiplo foco produtor de modelos de assistência e prestação de serviços a serem adotados pelas políticas públicas e pelos órgãos competentes da sociedade, empregando sua expertise na construção de parâmetros que apontem caminhos e soluções aos flagelos que nos assolam. Apenas uma instituição aberta aos problemas da sociedade pode ser sensível o bastante para empregar sua inteligência coletiva na produção de tais modelos de assistência e serviços. A humanidade, graças à evolução nas chamadas ciências exatas, conseguiu avanços tecnológicos significativos. Conseguimos estabelecer uma rede de comunicação mundial, mas não conseguimos diminuir a violência no nosso bairro e cada vez mais nossos jovens buscam nas drogas o prazer que não encontram na vida. Esse é um dos grandes desafios para as universidades: como transformar em "tecnologia" o conhecimento acumulado para que se possa enfrentar com eficiência os graves problemas sociais que nos afligem? Na busca da resposta a essa pergunta, as Ciências Humanas adquirirão papel fundamental.

Essa inteligência coletiva também tem a tarefa de desenvolver procedimentos de reconhecimento dos saberes adquiridos na vida social e profissional. A evolução do sistema de formação não pode ser dissociada da evolução do sistema de reconhecimento dos saberes que o acompanha. A avaliação, por sua vez, deve incluir critérios que extrapolem os clássicos sistemas avaliadores, praticados essencialmente como um procedimento técnico. Doravante, a avaliação tende a se tornar o que de fato ela é, em qualquer situação de nossas vidas: o processo pelo qual o valor se estabelece. A validação de um conhecimento apenas assegura que ele possa vir a ter valor para a sociedade, mas é a própria sociedade quem lhe dará ou não valor. Assim, serão os indivíduos que sempre se perguntarão: o que valem as ferramentas que utilizamos, o curso que estamos realizando, a instituição que freqüentamos?

Finalmente, o papel mais profundo das instituições, tanto no âmbito do ensino quanto da pesquisa, é sem dúvida o de formador do pensamento crítico. A sociedade desafia a instituição de ensino e pesquisa, cobrando-lhe uma verdadeira democracia cognitiva, a mais ampla que se pode conceber: a democracia do acesso à informação e aos conhecimentos. A instituição de ensino e pesquisa, a seu turno, está sendo convocada a estabelecer essa democracia cognitiva com toda a sociedade, instrumentalizandoa com seu potencial crítico, oferecendo-lhe referências e critério no trabalho com os conhecimentos.

Como acredita Freeman Dyson (2001), matemático e físico do Institute for Advanced Studies, da Universidade de Princeton, as três principais formas de se garantir justiça social no mundo do século XXI remetem à necessidade de se colocar as tecnologias a serviço da ética, à responsabilidade da política nas aplicações das ferramentas desenvolvidas pela ciência e às dificuldades e soluções para unir tecnologias e seres humanos em prol de uma vida mais digna para todos. Suas plenas realizações exigem pensamento crítico e democracia cognitiva. Todas são, igualmente, tarefas básicas da missão das instituições de ensino e pesquisa.

\section{REFERÊNCIAS BIBLIOGRÁFICAS}

AUTHIER, M. Pays de connaissances. Paris, Rocher, 1998a.

"Le bel avenir du parent pauvre". Apprendre à distance. Paris, Le Monde de L'Éducation de la Culture et de la Formation, 09/1998b.

DYSON, F. O Sol, o Genoma e a Internet. São Paulo, Companhia das Letras, 2001.

FOLHA DE S.PAULO. "Guia Pós-Graduação e MBA". Folha Empregos Especial 1. São Paulo, 03/02/2002.

LÉVY, P. Cibercultura. São Paulo, Editora 34, 1999.

SERRES, M, "La société pédagogique". Apprendre à distance. Paris, Le Monde de L'Éducation de la Culture et de la Formation, 09/ 1998.

Antonio Carlos Caruso Ronca: Reitor da Pontificia Universidade Católica de São Paulo.

RogÉRIO da Costa: Professor do Programa de Estudos Pós-Graduados em Comunicação e Semiótica da PUC/SP; Engenheiro de Sistemas e Computação. 